\title{
EMPOWERING NON-NATIVE ENGLISH SPEAKING TEACHERS THROUGH CRITICAL PEDAGOGY
}

\author{
Nur Hayati \\ (noer_du@yahoo.com) \\ Universitas Negeri Malang, Indonesia
}

\begin{abstract}
Critical pedagogy is a teaching approach that aims to develop students' critical thinking, political and social awareness, and self esteem through dialogue learning and reflection. Related to the teaching of EFL, this pedagogy holds the potential to empower non native English speaking teachers (NNESTs) when incorporated into English teacher education programs. It can help aspiring NNESTs to grow awareness of the political and sociocultural implications of EFL teaching, to foster their critical thinking on any concepts or ideas regarding their profession, and more importantly, to recognize their strengths as NNESTs. Despite the potential, the role of critical pedagogy in improving EFL teacher education program in Indonesia has not been sufficiently discussed. This article attempts to contribute to the discussion by looking at a number of ways critical pedagogy can be incorporated in the programs, the rationale for doing so, and the challenges that might come on the way.
\end{abstract}

Key words: critical pedagogy, teacher education, non native English teachers

During the 1980s, researchers and practitioners began to recognize that second language (L2) learning entails much more than developing language proficiency (Hinkel, 2005, p.891). They started to examine the complex relationships between social identity, culture, and power, and how these relate to the L2 learning (ibid, 2005). English language teaching is no longer seen merely as the language for international communication and commercial purposes as how it has been viewed in many non English speaking countries for quite a 
long time, probably until now; rather, it is also considered to bear power that has the potential to disempower non native English speakers' languages, cultures, and identities, and serves as a means to perpetuate colonialism. This argument is not without reason obviously. In India, for example, many young educated learners of today, who went to schools in which English is used as the medium of instruction cannot read and write in their first languages (Dheram, 2007, p.1). In Africa, access to English has not been equal, which contributes to the inequalities and injustice in many of the countries in the continent (Phan Le Ha, 2005). In Korea, a number of kids have undergone a tongue slashing surgery to remove their Korean accent (Shin, 2004). In Islamic world, "English as a Foreign Language (EFL) instruction does not often complement the cultures of its students or the local curricula" (Fredricks, 2007, p.23). Those are some of the cases where people see English and the cultures of English-speaking countries as superior, often downgrading and sacrificing their own languages and cultural values in the process of learning them.

Another form of injustice exists inside the field of English Language Teaching (ELT) due to the ideology which Holliday (2005) termed "nativespeakerism”. He defines it as "...a pervasive ideology within ELT, characterized by the belief that 'native-speaker' teachers represent a 'Western culture' from which spring the ideals both of the English language and ELT methodology” (2005, p.385). In many countries, non-native English speaking teachers (NNESTs) have faced discrimination in hiring practices and in demands for credibility in the work place (Maum, 2002). Their teaching qualification is often worth less than their accent and they need to prove their credibility to professionals in the field and their students, more than their native speaker counterparts (Thomas, 1999). This leads to potential problems of self-esteem among NNESTs (Medgyes, 1994, cited in Brutt-Griffler, 1999). Related to teaching methods, there has been a tendency of, as Seidlhofer (1999) puts it, a simple transfer of teaching approaches originating from English-speaking countries to countries where EFL is conducted.

These cases do not indicate that as ELT practitioners, we need to abandon the teaching of English to speakers of other languages (TESOL); rather, it signifies a call for change in the practice of TESOL. Instead of merely focusing on the development of students' language proficiency, it is high time that we

...doubt and be critical of the dominant discourse that represents the internationalization of English as good and as a passport to the first world; consider 
the relationship of [our] work to the spread of the language, critically evaluating the implications of [our] practice in the production and reproduction of social inequalities; and question whether [we] are contributing to the perpetuation of domination (Cox \& Peterson, 1999, p.439).

In other words, we need empowerment. This is one of the basic ideas of critical pedagogy, to empower the powerless. Critical pedagogy has its roots in the work of Paulo Freire (1970) who developed what so-called "Pedagogy of the Oppressed" in the education of illiterate adults in the third world so that they could "...become free subjects...to participate in the transformation of their society...” (Shaull, in Freire, 1993, p.11). The development of this pedagogy was obstructed when Freire was sent to exile. When he returned, the pedagogy came to its rebirth and was reproduced and reinterpreted by other scholars in different contexts (Cox \& Peterson, 1999). Duncan-Andrade and Morrell (2007) presents a nice summary of what critical pedagogy is in the following:

....an approach to education that is rooted in the experiences of marginalized peoples; that is centered in a critique of structural, economic, and racial oppression; that is focused on dialogue instead on a one way transmission of knowledge; and that is structured to empower individuals and collectives as agents for social change (p.183).

From the above definition, I would like to identify a number of elements that are the key to critical pedagogy, that is, critique, dialogue, empowerment and transformation. These elements I believe are relevant to be applied in other teaching contexts, especially in the contexts where changes are crucial. In this case, as some scholars and researchers have advocated, I see the need to adopt and adapt the concepts of critical pedagogy in the practice of TESOL. It should start from teacher education programs because teachers are the agents of this change, and they need to experience the pedagogy themselves as students. They need to be empowered before they can empower other people. In this article, I would like to examine the concepts of critical pedagogy in relation to TESOL and how these concepts have been applied in teacher education programs, consider the applicability of this pedagogy in my context and identify the potential challenges in the application. The discussion on the subjects involves critical analysis and synthesis of relevant case studies and concepts obtained mainly from peer-reviewed scholarly journal articles. Research findings 
and grounded theories from other sources, such as, handbooks and textbooks that have special significance to the topic are also included.

\section{APPLYING CRITICAL PEDAGOGY IN ESOL TEACHER EDU- CATION PROGRAMS}

Related to TESOL, I agree with Canagarajah's idea that critical pedagogy is not merely theories; rather, it is a strategy of teaching and learning (2005, p.932). He further explains that in practicing critical pedagogy, we need to put all aspects of our teaching under scrutiny to interrogate them in relation to power (ibid, p.932). English teachers need to make sure that what they do in the classroom does not contribute to the problems of inequalities in ELT, such as, unequal access to language learning, the belief that English and cultures associated to it are superior, and the ideology of native-speakerism. Rather, it should contribute to the construction of "more egalitarian, equitable, and ethical educational and social environments” (ibid, p.932).

English teachers should be made aware of the issues of power and inequality in the field of ELT because no change will be made unless people realize that it is necessary (Pennycook, 1999, p.336). Pennycook (1999, p.337) further points out, however, that this should not be a top-down attempt where instructors show their students how they are oppressed with minimum dialogue and reflection. This might be contra productive and would only make the students feel pessimistic and inferior. Consequently, as some researchers have done (see Crookes \& Lehner, 1998; Brutt-Griffler \& Samimy, 1999; Shin, 2004), it is important to incorporate the elements of problem posing, critical and reflective thinking, dialogue learning, and participatory approaches into the practice of critical pedagogy. Those researchers have shown that critical pedagogy can be used to promote prospective teachers' awareness of the ELT issues in broader contexts.

Crookes and Lehner (1998) took a more direct approach to engage their students in critical pedagogy. They set up an ESL Critical Pedagogy Teacher Education Course, in which the students were involved in the negotiation of the course content and the teaching and learning process, in which they explored their understandings and applications of critical pedagogy in the classroom, and in which their issues related to possible applications of critical pedagogy in their contexts are heard and posed to the whole class as problems to consider 
and as a means of reflection (pp.326-327). Throughout the course, there were indicators that the students started to develop awareness of the political and sociocultural issues surrounding the ELT and also learnt some ways in which this awareness might be raised in their own classes. Also, the course gives the students an opportunity to take part in the development of the program curriculum, which is a crucial element in applying critical approaches to TESOL (Pennycook, 1999, p.336).

Brutt-Griffler \& Samimy (1999) conducted a ten-week seminar for NNESTs which addressed specifically the issues related to native versus nonnative ELT professionals. It consisted of three main activities, that is, classroom dialogic, letter dialogic, and professional autobiography (p.420). The first activity involved classroom discussions where they talked about various issues regarding NESTs versus NNESTs. Here, they explored and shared their experiences, and reflected on them. They learnt from each other's experiences and ideas, and, as Byram \& Feng (2005, p.917) state, should go through a process of empowerment as they recognize that everyone's voice is heard and appreciated. The second activity in the seminar required the students to write a letter to a NNS scholar-professional, to question his assumptions on the issue of NESTs versus NNESTs. The goal of this activity was "to encourage the students to take part in the deconstruction of socially-imposed identities" (p.420), In this case, "questions of difference, identity, and culture are not merely issues to discuss but pertain to how people have come to be as they are, how discourses have structured people's lives” (Pennycook, 1999, p.340), and when these socially-imposed identities unnecessarily put them in the disadvantaged position, they obviously need to deconstruct it. Here, the learning activity of written dialogue reflects another important concept in critical pedagogy, that is, transformative education. Instead of merely transferring knowledge and values to students as in banking education, teachers facilitated the students to critically discuss real-world issues so that they can make improvements in the world they live in and develop themselves professionally (Crookes and Lahner, 1998, p.320). The last activity that was covered in the seminar was students' writing an autobiography. During the activity, the students, again, reflected on their experiences, saw how their identity as ELT professional has evolved throughout time, and how this evolution was affected by political and sociocultural contexts surrounding their profession. All those activities, I believe, can be adopted and/or adapted for teacher education programs in other contexts as it 
has shown some ways to empower NNESTs in dealing with the dichotomous notion of NESTs versus NNESTs and the disempowering socially-imposed identity and discourses of NNESTs through a shared process of reflective and critical thinking among the students.

Another case of the application of critical pedagogy that I would like to draw on here is the one Shin (2004) did with Korean teachers of English in a course called "Intercultural Communication for EFL Teachers: Teaching Cultures in the EFL Classroom". In this course, one of the most important goals was to empower students, who are all Korean teachers or aspiring EFL teachers, as speakers of English and as teachers of English (p.73). To achieve the goal, the students were to participate actively in problem posing activities. In one of the activities, the students were required to critically read articles on English as an International Language (EIL) and addressed the issues contained within the articles. One important issue discussed was related to what culture need to be taught in the EIL classroom. This was very much relevant with the ELT situation in Korea, where American cultures were the focus of the English lessons. Another issue emerging was related to the American English that has been widely used as the standard English in the ELT in Korea. The students were expected to learn from this activity that "English no longer belong to Inner Circle countries and that they are even as non-native speakers, legitimate speakers of English, thereby questioning the dominance of any kind of standard, linguistic or cultural, when learning or teaching English” (Shin, 2004, p.73). Besides reading articles and responding to them, students also did presentations on contrasting microcultures, in which they present their views on similarities and differences between NESTs and NNESTs, what intercultural communication problems that might occur between them, and how these problems could possibly be resolved (p.75). Shin concluded that the Freirian pedagogy applied in the course has helped the students to gain critical awareness of EIL and the power dynamics that exists in it, and to answer their questions on how to teach EIL in their contexts (2004, p.78).

The practice of critical pedagogy done by Crookes and Lehner (1998), Brutt-Griffler \& Samimy (1999), and Shin (2004) have been very inspiring for me as I am also a teacher educator in an undergraduate teacher education program, a novice one, who is still struggling with my identity as a NNEST but has a vision to apply critical pedagogy in my own context to empower the aspiring NNESTs I teach. I can relate to the programs they conducted, because 
ELT in Indonesia I think have similar problems in that as English teachers, we often are not aware enough of the political and sociocultural implications of our teaching, and we practice the banking education, transferring our ideas to the students about English with minimum process of dialogues and negotiation of meanings.

This is why I think critical pedagogy should be applied in teacher education programs in my context so that the prospective teachers taking the program are able to: (1) increase their awareness of their strengths as bilingual or multilingual speakers of English and how these strengths can be profitably used in the classroom (e.g. the use of mother tongue in facilitating learning); (2) increase their awareness of native-speaker fallacy so as not, for example, judging their students' performance based on their accent or feeling inferior because of their coming from non English speaking countries; (3) develop knowledge and skills to assist their future students in learning English to be able to communicate with the world without losing their identity (Pham Hoa Hiep, 2000, cited in Phan Le Ha, 2008); (4) develop the ability "to evaluate ELT materials critically to ensure that these do not, either explicitly or implicitly, promote a particular variety of English or culture at the expense of others" (Kirkpatrick, 2006, p.33) ; (5) develop knowledge and skills to appropriate methodology with local contexts and students' needs; (6) develop knowledge of different varieties of English and in turn, help their students to increase awareness of the varieties (Kirkpatrick, 2006); and (8) develop English competence in an established variety of English which they are most comfortable with and is intelligible to other people.

In my opinion, these aims can be achieved by conducting courses that discuss the current development of English language teaching, not merely the development of teaching methods and materials, but also the political and sociocultural contexts within which ELT is located. In other words, we need to "connect TESOL to questions of power, inequality, discrimination, resistance, and struggle” (Pennycook, 1999, p.332). 


\section{DEALING WITH CHALLENGES}

Applying critical pedagogy in ESOL Teacher Education Programs may sound very political and might receive opposition and challenges from students and colleagues, especially in Indonesia, where people are getting tired of politics, and many of them might think that politics should not go into the English classroom. They probably much rather have these assumptions "that language teaching is neutral, sterile, and organic; that it has nothing to do with politics and power; that teachers should avoid 'hot' topics or touchy issues" (Brown, 2004, p.23). I think the solution to this problem lies on the careful planning of the course. When the materials of the course are carefully selected, considering its relevance to the students' professional lives, possibly involving the students in the selection, I believe that the courses would be able to stimulate the students' interest on the issues concerned. This should be combined with the development of supportive learning atmosphere which incorporate the basic principles of Freire's critical pedagogy, so that the learning activities are democratic, interactive and cooperative, involves dialogues and discussions, addresses the complexity of the multicultural society, encourages critical thinking both in personal and social reflection, situated in "students' language, events, and culture", combines with classroom and community research by teacher and students (Shor, 1992, cited in Brutt-Griffler, 1999, p.420), and includes "a means of transformation” (Pennycook, 1999, p.335).

And so the materials have been carefully selected, and the instructor has had enough ideas of how the courses are to be conducted; however, the reality may not be that simple. Another challenge for teacher educators who apply critical pedagogy is that many of the students might not be used to the idea of problematizing things, questioning assumptions, and things like that, especially when these relate to "assumptions [and] ideas that have become naturalized, [and] notions that are no longer questioned" (Pennycook, 1999, p.343) and moreover, when these concern sensitive subjects like race, religion, ethnicity, or gender. Indonesia was ruled by an authoritarian regime for tens of years, when people did not have freedom to criticize the government, when the richer and the more powerful can do whatever they want, and when people were exposed to false image of the regime through mass media and even, school textbooks. This alienation of critique and the suppression of sensitivity toward so- 
cial issues seemed to have penetrated in the educational system as well. It is understandable, therefore, that students might find difficulties with the idea of critical work, especially when considering that in their previous learning of English, they probably never encountered the idea. Teachers might need to anticipate lots of silent moments in the classroom by figuring out some ways they can encourage the students to express their ideas. Students might be asked to write down their views or do some group works prior to the classroom discussion. These can also be used to deal with the problem of confidence and language proficiency that can often be found in an EFL classroom. More importantly, teachers need to give opportunities for the students to analyze both sides of the issues discussed, especially when these issues are considered sensitive (Brown, 2004). Brown also emphasizes the need to "create an atmosphere of respect for each other's opinions, beliefs, and ethnic or cultural diversity in the classroom" (2004, p.23). He further asserts an interesting idea that classroom should be "a model of the world as a context for tolerance and for the appreciation of diversity" (ibid, p.23). In this case, it is not impossible that classroom can promote social change.

Other concerns over critical pedagogy that may challenge its application include the worries that the students might become overly critical, problematize everything, and become biased toward NESTs or certain cultures. They may also develop new stereotypes or make overgeneralizations that put other groups in a disadvantaged position. This is an important issue that needs to be addressed in the classroom, so that students are aware of the concerns and not to fall into the holes. They should also be encouraged to discuss ways in which differences can be negotiated, that diversity can exist within unity, and that there are always two sides of a coin.

\section{CONCLUDING REMARKS}

In conclusion, I believe critical pedagogy should be given a place in the curriculum of English teacher education in my country, manifested through courses designed to enable the students to locate aspects of TESOL within a broader, critical view of social and political relations (Pennycook, 1999, p.332). Aspiring NNESTs should be educated in ways that increase their self esteem and critical thinking and lead them to have awareness of political and sociocultural issues and desire to make social changes - ways that empower 
them. Such courses thus need to engage the students in learning activities that involve problem posing, dialogue learning and reflective thinking. Finally, the courses should be carefully planned by considering the provision of required resources, the selection of appropriate materials and learning activities and the

solutions to problems and challenges that might come up during the application.

\section{REFERENCES}

Brown, H. D. 2004. Some Practical Thoughts about Student-sensitive Critical Pedagogy. The Language Teacher Online, 28 (7): 23-27. Retrieved May 30, 2008, from http://www.jalt-publications.org/tlt/articles/2004/07/brown

Brutt-Griffler, J., \& Samimy, K. (1999). Revisiting the Colonial in the Postcolonial: Critical Praxis for Non-Native English Speaking Teachers in a TESOL Program. TESOL Quarterly, 33 (3): 413-431.

Byram, M., \& Feng, A. 2005. Teaching and Researching Intercultural Competence. In E. Hinkel (Ed.). Handbook of Research in Second Language Teaching and Learning (pp. 911-930). New Jersey: Lawrence Erlbaum Associates, Inc.

Canagarajah, S. 2005. Critical Pedagogy in L2 Learning and Teaching. In E. Hinkel (Ed.). Handbook of Research in Second Language Teaching and Learning (pp.931-949). New Jersey: Lawrence Erlbaum Associates, Inc.

Cox, M. I. P., \& Peterson, A. A. D. A. 1999. Critical Pedagogy in ELT: Images of Brazilian Teachers of English. TESOL Quarterly, 33 (3): 433-452.

Crookes, G., \& Lehner, A. 1998. Aspects of Process in an ESL Critical Pedagogy Teacher Education Course. TESOL Quarterly, 32 (2): 319-328.

Dheram, P. 2007. Empowerment Through Critical Pedagogy. Academic Leadership: The Online Journal, 5 (2). Retrieved May 30, 2008, from http://www.academicleadership.org/emprical_research/Empowerment_thr ough_Critical_Pedagogy.shtml

Duncan-Andrade, J., \& Morrell, E. 2007. Critical Pedagogy and Popular Culture in an Urban Secondary English Classroom. In P. McLaren, \& J.L. 
Kincheloe (Eds.). Critical Pedagogy: Where are We Now? (pp.183-199) (Vol. 299). New York: Peter Lang Publishing, Inc.

Fredricks, L. 2007. A Rationale for Critical Pedagogy in EFL: The Case of Tajikistan. The Reading Matrix, 7(2): 22-28.

Freire, P. 1993. Pedagogy of the Oppressed (M.B. Ramos, Trans.). New York: Continuum.

Hinkel, E. 2005. Identity, Culture, and Critical Pedagogy in Second Language Teaching and Learning: Introduction. In E. Hinkel (Ed.). (2005). Handbook of Research in Second Language Teaching and Learning. New Jersey: Lawrence Erlbaum Associates, Inc. pp.891-893

Holliday, A. 2005. The Struggle to Teach English as an International Language. Oxford: Oxford University Press.

Johnston, B. 1999. Putting Critical Pedagogy in its Place: A personal Account. TESOL Quarterly, 33(3): 557-565.

Kirkpatrick, A. 2006. Teaching English Across Cultures: What do English Teachers Need to Know to Know How to Teach English EA Journal, 23(2): 20-36.

Maum, S. 2002. Non-native English Speaking Teachers in the English Profession [Electronic Version]. CAL Digest on English as a Second Language and Professional Development,

Pennycook, A. 1999. Introduction: Critical Approaches to TESOL. TESOL Quarterly, 33(3): 329-348.

Phan Le Ha. 2005. Toward a Critical Notion of Appropriation of English as an International Language [Electronic Version]. Asian EFL Journal, 7. Retrieved May 15, 2008, from www.asian-efl-journal.com/September_05_plh.php

Phan Le Ha. 2008 Teaching English as an International Language, Identity, Resistance and Negotiation. Clevedon: Multilingual Matters Ltd.

Seidlhofer, B. 1999. Double Standards: Teacher Education in Expanding Circle. World Englishes, 18 (2): 223-245. 
Shin, J. K. 2004. The Use of Freirian Pedagogy in Teaching English as an International Language [Electronic Version]. LLC Review, 64-82. Retrieved June 1, 2008, from www.umbc.edu/llc/llcreview/2004/The_Use_of_Freirian_Pedagogy.pdf

Thomas, J. 1999. Voices From the Periphery: Non-native Teachers and Issues of Credibility. In G. Braine (Ed.). (1999). Non-native Educators in English Language Teaching (pp.5-13). New Jersey: Lawrence Erlbaum Associates, Inc. 